\title{
Association of Obstructive Parameters of Lung Functions Estimated by Spirometry with Risk Factors for Cardiovascular Disease among Women of Tertiary Care Hospital
}

\author{
Kommu Kavya ${ }^{1}$ Archana Mavoori ${ }^{2}$ \\ Swapna D. ${ }^{3}$ Madhuri Taranikanti ${ }^{3}$

\footnotetext{
${ }^{1}$ Department of Physiology \& General Medicine, ESIC Medical College, Sanathnagar, Hyderabad, Telangana, India

${ }^{2}$ Department of Dermatology, Venereology and Leprosy, ESIC Medical College, Sanathnagar, Hyderabad, Telangana, India

${ }^{3}$ Department of Physiology, ESIC Medical College, Sanathnagar, Hyderabad Telangana, India
}

\author{
Aswin Kumar M. ${ }^{3}$ Farheen Fatima $^{3}$ Vaishali M. Pauniker ${ }^{3}$
}

Ind J Car Dis Wom:2020;5:299-304

\begin{abstract}
Address for correspondence Kommu Kavya, II MBBS, HNO:1327/8/B, Chiranjeevi Nagar, Miyapur, Hyderabad, Telangana, India (e-mail: kavyambbs7@gmail.com).
\end{abstract}

\begin{abstract}
Keywords

- obstructive lung function

- pulse wave velocity

- hypertension

- pulse pressure

Background Declining lung functions is associated directly with cardiovascular diseases like heart failure or coronary artery disease, or the risk factors leading to cardiovascular mortality like arterial stiffness, pulse wave velocity, hypertension, etc. Exclusive studies in women are not frequently performed.

Aim The aim is to study the association between obstructive lung function estimated through spirometry and cardiovascular risk indicators like hypertension and arterial pulse wave velocity measured between carotid and femoral arteries (cf-PWV) in women. Methods A total of 30 postmenopausal women on regular treatment for hypertension were recruited in the study. They were subjected to spirometry and computerized cf-PWV estimation. Women were grouped according to modified global initiative for chronic obstructive lung disease (GOLD) criteria into three groups with increasing severity of obstructive lung function.

Results Diastolic blood pressure $(p=0.04)$, pulse pressure $(p<0.0001)$, and cf-PWV $(p=0.009)$ were found to be significantly different between the three groups. Negative correlation existed between cf-PWV and \%pred forced expiratory volume in 1 second (FEV1) in the group with most severe obstructive lung function (Pearson correlation coefficient $r=0.7610$ was significant at $p=0.01$ ). The strength of this negative association decreased as the severity deceased $(r=0.5603$, significant at $p=0.03)$.

Conclusion Strong association between severity of obstructive lung function in postmenopausal women with pulse pressure was in lines with previous studies, but the diastolic blood pressure being associated is a novel finding. Also, the degree of obstructive lung function is positively associated with arterial stiffness which is an important indicator for impending cardiovascular mortality.
\end{abstract}

\section{Introduction}

Ischemic heart disease and cerebrovascular disease are two major causes of death worldwide. Chronic obstructive pulmonary disease is expected to be the third leading cause of worldwide mortality by 2020 and fifth major cause of disability. ${ }^{1}$ Cardiovascular mortality is proportional to co-existing morbidities and chronic obstructive pulmonary disease (COPD) is most important amongst them. published online

March 16, 2020
DOI https://doi.org/

10.1055/s-0040-1705662.
(C)2020. Women in Cardiology and Related Sciences.

This is an open access article published by Thieme under the terms of the Creative Commons Attribution-NonDerivative-NonCommercial-License, permitting copying and reproduction so long as the original work is given appropriate credit. Contents may not be used for commercial purposes, or adapted, remixed, transformed or built upon. (https://creativecommons.org/licenses/by-nc-nd/4.0/).

Thieme Medical and Scientific Publishers Pvt. Ltd. A-12, 2nd Floor, Sector 2, Noida-201301 UP, India 
Cardiovascular mortality has been shown to be up to twofold greater in patients with obstructive lung diseases than in a matched group without any lung disease. Research also suggested that the systemic inflammation plays some key role in the pathogenesis of the lung diseases and cardiovascular diseases. Few studies showed that biomarkers for endothelial dysfunction and inflammation like soluble intracellular adhesion molecule-1, fibrinogen, high sensitivity C-reactive protein (HsCRP), interleukin-6 (IL-6) were involved in the mediation of loss of elasticity in small and medium arteries and such patients showed significant reductions in forced vital capacity (FVC) and forced expiratory volume in 1 second (FEV1). Especially HsCRP and IL-6 have been carefully monitored over years in few studies. Alterations in cardiovascular disease risk due to affected arterial elasticity were shown to be one of the reasons for the cardiovascular diseases. ${ }^{2}$ Arterial stiffness which was produced by the loss of elasticity has been correlated with impaired lung functions. Relationship between pulse pressure (PP) as an important marker for arterial stiffness was studied by few authors. ${ }^{3}$ Brachial-ankle pulse wave velocity and ankle-brachial index were shown to be inversely and dose-dependently associated with arterial stiffness in a group of older Chinese subjects. ${ }^{4}$ It was found that poorer lung function as shown by reduced FEV1 was strongly associated with arterial stiffness as indicated by carotid to femoral pulse wave velocity (cf-PWV) in a large group when followed up for approximately 5 years. ${ }^{5}$ Hypertension was shown to be variably associated with poor lung function due to restriction as well as obstructive type. ${ }^{6,7} \mathrm{Few}$ authors investigated the relation between declined lung function as shown by low FEV1 or FVC values and cardiovascular disease considered in a composite of many independent diseases like stroke, coronary arterial disease, heart failure, ventricular hypertrophy. ${ }^{89}$ Arterial stiffness played a major role in the pathogenesis of chronic heart failure and low FEV1 values. ${ }^{10}$ It has been found that, interestingly, the combination of hypertension and the usage of antihypertensive medication had the strongest negative effect on lung function. ${ }^{11}$ Correlations between total lung capacity (TLC) and the increased pulse wave velocity were also established. ${ }^{12}$

\section{Materials and Methods}

The study sample consisted of 30 females in the age group of 40 to 60 years with mean age of $50.6 \pm 8$ years. All women were postmenopausal. None of them were on hormone replacement therapy. Out of the 30 patients 28 were known hypertensives using standard dosages of antihypertensive medicationtelmisartan and amlodipine and standard dosages of medication for COPD-theophylline and salbutamol. Eighteen of them were educated up to high school and 12 were uneducated. All the subjects were urban residents and working on daily wages. The nature of work is moderate to heavy as per the history. They were referred from the general medicine OPD to the pulmonary function department around $10 \mathrm{am}$ to 12 noon. This time is chosen because the circadian variations in the pulmonary function tests will be minimal. ${ }^{13}$
Exclusion criteria followed in selection of the subjects:

- Presence of active lung infection like pneumonia, pleural effusion, cough with expectoration, fever, etc. and having any previously diagnosed restrictive lung disease.

- Presence of severe cardiovascular disease like heart failure, coronary artery disease, valvular heart disease, history of angioplasty, stroke.

- Presence of upper respiratory tract infections like tonsillitis, middle ear infections, sinusitis, etc.

- Severe uncontrolled hypertension, abdominal pathology like tumors, gastric ulcers, and liver disease.

- Diabetes mellitus.

- Smoking and exposure to biomass fuel smoke.

Inclusion criteria followed in the selection of the subjects:

- Diagnosed with clinical obstructive lung disease.

- Not having any previously diagnosed cardiovascular disease, although hypertensives are included as raised blood pressure is just a risk factor for imminent cardiovascular diseases.

As they arrived in the pulmonary function testing department they were made to relax for 10 minutes before beginning the test to reduce their anxiety and exertion. It was confirmed that they did not had any heavy meal and did not take any bronchodilator inhalation before arriving in the department. After taking their informed written consent and explaining them about the technique in the language understandable by them, their resting blood pressure was measured using a standard mercury sphygmomanometer in sitting position. Three readings with 5-minute gap were recorded and the average reading was considered. Chest auscultation was done to rule out any cardiovascular pathology. The pulmonary function tests were performed using the Spiroexcel software. The guidelines followed in this study were in line with Joint Indian Chest SocietyNational College of Chest Physicians (India) guidelines for spirometry. ${ }^{14}$ They were asked to take a deep inspiration in sitting position and exhale forcibly into the mouthpiece by closing their nostrils and sealing the mouth with their hand. Three readings were taken from each patient and the best out of them was selected and print was obtained. Required precautions were taken to use the sterilized mouthpieces for each patient. After performing the spirometry tests the patients were asked to lie supine on the couch for $5 \mathrm{~min}$ utes. Blood pressure cuffs were tied at both brachial and ankle sites, echocardiography was recorded from Lead II and the data were fed into the software provided by the Diabetes Risk Profiler, to calculate pulse wave velocity between carotid and femoral points (cf-PWV). The subjects were later divided into three groups based on the global initiative for chronic obstructive lung disease (GOLD) criteria, as all the 30 subjects included were diagnosed and being treated with obstructive lung disease both by the physician and confirmed by the spirometry results. The lower limit of normal was considered during the classification of the women into the groups. ${ }^{15}$ The modified GOLD criteria as used by few authors were used in our study. ${ }^{1}$ 
GOLD 3 or 4 included patients with FEV1 predicted value $<50 \%$, GOLD 2 with $>50 \%$ to $<80 \%$, and GOLD 1 with $>80 \%$ predicted value. No patients were found with GOLD 0 criteria, that is, presence of only respiratory symptoms without lung function abnormality. Various lung function parameters like FVC, FEV1, peak expiratory flow rate (PEFR), ratio of FEV1/FVC, fraction of FEV (forced expiratory flow [FEF] 25-75) were measured. For the analysis, the percentage of predicted value of a particular parameter was only used.

\section{Results}

Six women were present in the group with GOLD 1 criteria, 14 in GOLD 2 group, 10 in GOLD 3 or 4 group. Our results indicate the presence of increased pulse wave velocity and rise of diastolic blood pressure (DBP). The mean systolic blood pressure (SBP) and DBP were calculated in the GOLD criteria groups. The mean SBP did not show much difference across the groups. DBP was found to be significantly different between GOLD 3 or 4 group with $100.4 \pm 17.2 \mathrm{~mm} \mathrm{Hg}$ and GOLD 2 group with $89 \pm 11 \mathrm{~mm} \mathrm{Hg}(p=0.04)$, and with GOLD 1 group with $89 \pm 4 \mathrm{~mm} \mathrm{Hg}$ (-Table 1). A significant difference in the diastolic blood pressure is the novel finding in our study in contrast to previous studies which reported SBP difference. When the means of the PP and mean arterial pressure (MAP) were calculated, it was found that mean difference in PP between the GOLD 1 and GOLD 3 or 4 groups and between GOLD 2 and 3 or 4 groups was highly significant $(p<0.0001)$ which suggests that PP is a better index for severity in lung function as found out by previous studies. ${ }^{3}$ However, such significant difference in means was not observed in MAPs but MAP remained high in the third group ( - Table 2 ). The mean body mass index (BMI) did not affect the lung functions in these women (-Table 3 ). When the cf-PWV were estimated, women with the severe obstruction in GOLD 3 or 4 group showed mean cf-PWV $(\mathrm{cm} / \mathrm{s})$ as $1,395.97 \pm 235.65$, followed by $1,263.92 \pm 178.09 \mathrm{~cm} / \mathrm{s}$ in GOLD 2 group and $1,113.08 \pm 133.89 \mathrm{~cm} / \mathrm{s}$ in GOLD 1 group. These differences in the cf-PWV were significant across the groups (-Tables 3, 4).

The means with standard deviations were calculated for the three groups for various parameters like percentage of predicted values for forced vital capacity (\%FVC pred), forced expiratory volume in first second (\%pred FEV1), ratio of FEV1 to FVC (\%pred FEV1/FVC), peak expiratory flow rate (\%pred PEFR), fraction of FEV between 25 and $75 \%$ volumes (\%pred FEF 25-75). All the means were significantly different between the groups (-Tables 5, 6). A negative correlation between cf-PWV and \%pred FEV1 values was observed in the group with GOLD

Table 1 Means and SD values of blood pressure in various groups

\begin{tabular}{|l|l|l|l|l|}
\hline Group & $\begin{array}{l}\text { SBP }(\mathrm{mm} \mathrm{Hg}) \\
(\text { mean } \pm \text { SD) }\end{array}$ & $\begin{array}{l}\text { DBP }(\mathbf{m m ~ H g}) \\
(\text { mean } \pm \text { SD) }\end{array}$ & $\begin{array}{l}\text { Pulse pressure }(\mathrm{mm} \mathrm{Hg}) \\
(\text { mean } \pm \text { SD) }\end{array}$ & $\begin{array}{l}\text { Mean arterial pressure }(\mathrm{mm} \mathrm{Hg}) \\
(\mathrm{mean} \pm \mathrm{SD})\end{array}$ \\
\hline GOLD 1 & $135 \pm 8$ & $89 \pm 4$ & $46 \pm 4$ & $104.3 \pm 5.3$ \\
\hline GOLD 2 & $137.9 \pm 18$ & $89 \pm 11$ & $48.93 \pm 7$ & $105.31 \pm 13.3$ \\
\hline GOLD 3 or 4 & $132 \pm 19$ & $100.4 \pm 17$ & $31.66 \pm 1.8$ & $110.95 \pm 17.8$ \\
\hline
\end{tabular}

Abbreviations: DBP, diastolic blood pressure; GOLD, global initiative for chronic obstructive lung disease; SBP, systolic blood pressure; SD, standard deviation.

Table 2 Significance levels between the means of blood pressures compared amongst the GOLD criteria

\begin{tabular}{|l|l|l|l|l|}
\hline Group & SBP $(\mathbf{m m ~ H g})$ & DBP $(\mathbf{m m ~ H g})$ & Pulse pressure $(\mathbf{m m ~ H g})$ & Mean arterial pressure $(\mathrm{mm}$ Hg) \\
\hline $\begin{array}{l}\text { GOLD } 3 \text { or } 4 \text { and } \\
\text { GOLD } 2\end{array}$ & $\begin{array}{l}p=0.2282 \\
\text { not significant }\end{array}$ & $\begin{array}{l}p=0.0432 \\
\text { significant }\end{array}$ & $\begin{array}{l}p<0.0001 \\
\text { significant }\end{array}$ & $\begin{array}{l}\text { not significant } \\
\text { GOLD } 3 \text { or } 4 \text { and }\end{array}$ \\
$\begin{array}{l}\text { GOLD } 1 \\
\text { not significant }\end{array}$ & $\begin{array}{l}p=0.3375 \\
\text { significant }\end{array}$ & $\begin{array}{l}p<0.0001 \\
\text { significant }\end{array}$ & $\begin{array}{l}p=0.1468 \\
\text { not significant }\end{array}$ \\
\hline
\end{tabular}

Abbreviations: DBP, diastolic blood pressure; GOLD, global initiative for chronic obstructive lung disease; SBP, systolic blood pressure.

Table 3 Means and SD values of BMI and cf-PWV in various groups

\begin{tabular}{|l|l|l|}
\hline Group & $\begin{array}{l}\text { BMI }\left(\mathrm{kg} / \mathrm{m}^{-2} \text { ) }\right. \\
\text { (mean } \pm \text { SD) }\end{array}$ & $\begin{array}{l}\text { cf-PWV }(\mathrm{cm} / \mathrm{s}) \\
\text { (mean } \pm \text { SD) }\end{array}$ \\
\hline GOLD 1 & $30.36 \pm 3.23$ & $1113.08 \pm 133.89$ \\
\hline GOLD 2 & $27.34 \pm 4.01$ & $1263.92 \pm 178.09$ \\
\hline GOLD 3 or 4 & $26.62 \pm 4.23$ & $1395.97 \pm 235.65$ \\
\hline
\end{tabular}

Abbreviations: BMI, body mass index; cf-PWV, carotid to femoral pulse wave velocity; GOLD, global initiative for chronic obstructive lung disease; SD, standard deviation.
Table 4 Significance levels between the means between BMI and cf-PWV compared amongst the GOLD criteria

\begin{tabular}{|l|l|l|}
\hline Group & BMI $\left(\mathrm{kg} / \mathrm{m}^{2}\right)$ & cf-PWV $(\mathrm{cm} / \mathrm{s})$ \\
\hline $\begin{array}{l}\text { GOLD } 3 \text { or } 4 \text { and } \\
\text { GOLD } 2\end{array}$ & $\begin{array}{l}p=0.3397 \\
\text { not significant }\end{array}$ & $\begin{array}{l}p=0.0780 \\
\text { not quite significant }\end{array}$ \\
\hline $\begin{array}{l}\text { GOLD } 3 \text { or } 4 \text { and } \\
\text { GOLD } 1\end{array}$ & $\begin{array}{l}p=0.0349 \\
\text { significant }\end{array}$ & $\begin{array}{l}p=0.0091 \\
\text { very significant }\end{array}$ \\
\hline
\end{tabular}

Abbreviations: BMI, body mass index; cf-PWV, carotid to femoral pulse wave velocity; GOLD, global initiative for chronic obstructive lung disease. 
Table 5 Means and SD values of various pulmonary function test parameters amongst the three groups with GOLD criteria

\begin{tabular}{|l|l|l|l|l|l|}
\hline $\begin{array}{l}\text { Parameter } \\
\text { recorded from } \\
\text { pulmonary } \\
\text { function test }\end{array}$ & $\begin{array}{l}\text { \%FVC pred } \\
\text { (mean } \pm \text { SD) }\end{array}$ & $\begin{array}{l}\text { \%FEV1 pred } \\
\text { (mean } \pm \text { SD) }\end{array}$ & $\begin{array}{l}\text { \%FEV1/FVC pred } \\
\text { (mean } \pm \text { SD) }\end{array}$ & $\begin{array}{l}\text { \%PEFR pred } \\
\text { (mean } \pm \text { SD) }\end{array}$ & $\begin{array}{l}\text { \%FEF 25-75 pred } \\
\text { (mean } \pm \text { SD) }\end{array}$ \\
\hline GOLD 1 & $86.72 \pm 20.8$ & $93.88 \pm 17.7$ & $114.46 \pm 8.79$ & $77.09 \pm 18.4$ & $92.82 \pm 23.84$ \\
\hline GOLD 2 & $65.86 \pm 9.13$ & $65.18 \pm 16.10$ & $103.96 \pm 21$ & $55.24 \pm 17.61$ & $53.16 \pm 28.1$ \\
\hline GOLD 3 or 4 & $53.04 \pm 22$ & $28.69 \pm 17.8$ & $65.89 \pm 41$ & $33.59 \pm 13$ & $34.05 \pm 18.81$ \\
\hline
\end{tabular}

Abbreviations: FEF, forced expiratory flow; FEV1, forced expiratory volume in 1 second; FVC, forced vital capacity; GOLD, global initiative for chronic obstructive lung disease; PEFR, peak expiratory flow rate; SD, standard deviation.

Table 6 Significance levels between the means of various pulmonary function test parameters compared amongst the GOLD criteria

\begin{tabular}{|l|l|l|l|l|l|}
\hline $\begin{array}{l}\text { Parameter } \\
\text { recorded from } \\
\text { pulmonary } \\
\text { function test }\end{array}$ & \%FVC pred & \%FEV1 pred & \%FEV1/FVC pred & \%PEFR pred & \%FEF 25-75 pred \\
\hline $\begin{array}{l}\text { GOLD 3 or } 4 \text { and } \\
\text { GOLD 2 }\end{array}$ & $\begin{array}{l}p=0.0550 \\
\text { not significant }\end{array}$ & $\begin{array}{l}p<0.0001 \\
\text { extremely } \\
\text { significant }\end{array}$ & $\begin{array}{l}p=0.0195 \\
\text { significant }\end{array}$ & $\begin{array}{l}p=0.0023 \\
\text { significant }\end{array}$ & $\begin{array}{l}p=0.0592 \\
\text { not significant }\end{array}$ \\
\hline $\begin{array}{l}\text { GOLD 3 or } 4 \text { and } \\
\text { GOLD 1 }\end{array}$ & $\begin{array}{l}p=0.0053 \\
\text { significant } \\
\text { extremely } \\
\text { significant }\end{array}$ & $\begin{array}{l}p=0.0048 \\
\text { significant }\end{array}$ & $\begin{array}{l}p=0.0010 \\
\text { significant }\end{array}$ & $\begin{array}{l}p=0.0009 \\
\text { significant }\end{array}$ \\
\hline
\end{tabular}

Abbreviations: FEF, forced expiratory flow; FEV1, forced expiratory volume in 1 second; FVC, forced vital capacity; GOLD, global initiative for chronic obstructive lung disease; PEFR, peak expiratory flow rate.

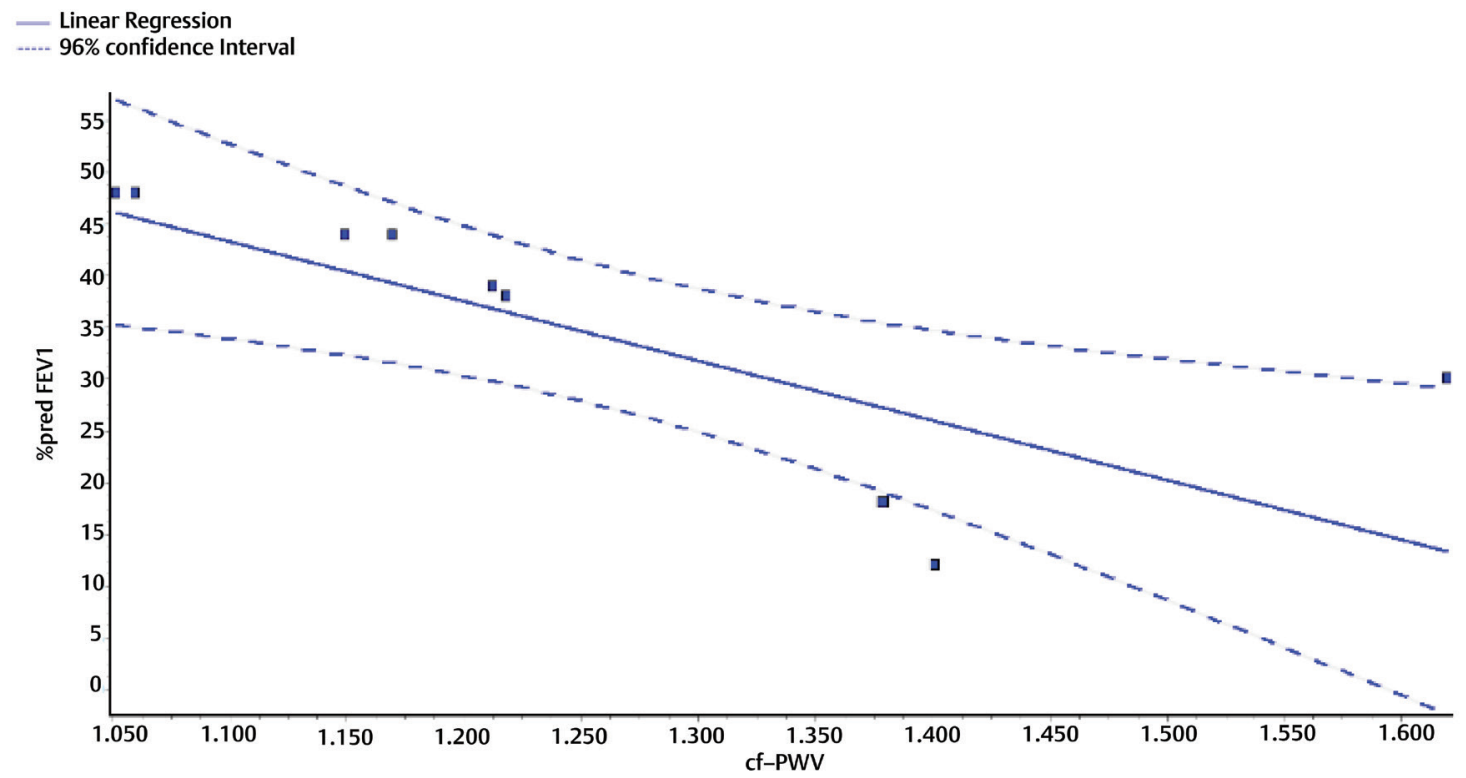

Fig. 1 Linear regression analysis between the \%pred FEV1 values and corresponding cf-PWV values in GOLD 3 or 4 group with severe obstructive lung function. cf-PWV, carotid to femoral pulse wave velocity; FEV1, forced expiratory volume in 1 second; GOLD, global initiative for chronic obstructive lung disease.

3 or 4 criteria with linear regression analysis $(r=0.7610)$. This correlation was found significant $(p=0.01 ;-$ Fig. 1$)$. Similar correlation was observed in the group with GOLD 2 criteria. The correlation coefficient $r=0.5603$ was considered significant $(p=0.03)$. Also, in this group with GOLD 2 criteria, a significant correlation was also found between the cf-PWV and \%pred FVC values. However, in the group with GOLD 1 criteria, there was no significant correlation between cf-PWV and any of the parameters with $r=0.69$ which is not significant $(p=0.12)$. 


\section{Discussion}

Women in their postmenopausal period are prone to many metabolic and organ dysfunctions. Dyslipidemia, hypertension, obesity, cardiovascular diseases are few of these dysfunctions. In the present study, postmenopausal women are recruited to study the interrelation of the dysfunctions between lung and cardiovascular diseases. In women with hypertension and known obstructive lung impairment, it has been studied how much strong the association is between the intensity of the lung disease and the cardiovascular risk indicators, hypertension and cf-PWV in this study. All the subjects were found to have obstructive lung disease and have been classified using GOLD criteria. Also, they were on standard medication for hypertension and COPD. The drugs being used for the COPD, theophylline, and salbutamol have their own effects on cardiovascular status. Theophylline is relatively safe drug in COPD with no side-effects and hence, its effect as a confounding factor was not studied. ${ }^{16}$ Salbutamol has been reported to effect the cardiovascular system by producing tachycardia, arrhythmias, heart failure, and other morbidities. ${ }^{17}$ However, in the present study group, no side-effects which could be ascribed to salbutamol usage and present a confounding effect on the findings were observed. Observed changes in cf-PWV and blood pressure suggest that they are more likely independent of salbutamol effect. Difference in SBP across the groups was not statistically significant contrary to the previous studies..$^{12}$ DBP which is an indicator of increased damage to the heart has been strongly associated with impaired lung functions. The increase in the DBP could be due to concomitant arteriosclerosis in these hypertensive women or may be somehow induced by hypoxic stimuli to brain causing sympathetic activation. ${ }^{18}$ This raises a question whether the lung pathology is older than the hypertension and may be due to chronic obstruction and consequent hypoxia, the sympathetic activation led to hypertension. The hypertensive women have been on medication, but the diastolic pressures are kept raised probably due to ongoing hypoxic stimulus as the lung disease is not addressed. The pulse wave velocity, which is an important indicator of arterial stiffness was found to be positively associated with the severity of the obstructive lung pathology. The group with most severe obstruction (GOLD 3 or 4) was found to have cf-PWV values around $1,395.97 \pm 235.65 \mathrm{~cm} / \mathrm{s}$ compared with GOLD 1 group having around 1,113.08 $\pm 133.89 \mathrm{~cm} / \mathrm{s}$. This means, approximately $30 \%$ reduction in the predicted value of FEV1 in the severe obstruction group led to roughly $25 \%$ increase in the velocity, which is ascribed to arterial stiffness, especially the central large vessels (as it is measured between carotid-femoral vessels) which are comprised of elastic tissue. We suppose that the obstructive lung disease must have begun quite earlier in the life in these women thus leading to chronic hypoxia, which must have gone neglected owing to their daily life demands. As most of them were daily wage workers ( $80 \%$ ) physical work becomes a necessity for them for survival. The underlying lung pathology must have gone unnoticed or neglected even though intermittent bursts of hypoxia upon exacerbation of lung disease must have been experienced. The chronically present obstructive disease could have caused central sympathetic activation through hypoxic stimulation of regulatory centers. Also, local inflammatory mediators must have been produced in the lung increasing their levels gradually in the blood leading to slow endothelial injury and loss of elasticity of central large vessels. ${ }^{2}$ As the women now reach their postmenopausal period and are probably prone to altered lipid levels in the blood, they are under the heavy risk of developing cardiovascular mortality added by the elasticity changes in the vasculature.

Therefore, finding the association between the declined lung functions in women with hypertension necessitates that lung function tests must be initiated at a very early stage in all groups of people coming to the hospital as a routine screening test to rule out any underlying obstructive or restrictive pathology. Our study strongly recommends that this should be made a routine practice in all hospitals. Imbalance in the synchronized functioning between heart and lung leads to pathology. Therefore, it is also very much required to assess the cardiorespiratory physiological parameters like respiratory sinus arrhythmia, heart rate variability, etc. in such women diagnosed with either obstructive or restrictive lung diseases. These tests will also aide in the assessment of severity of the current disease and the future risks associated. Many studies done previously trying to find an association between lung impairment and cardiovascular diseases proposed a common process where inflammation plays a key role. Inflammatory mediators like IKL-6, TNF $\alpha$, fibrinogen, etc. were elevated in people with such scenario. ${ }^{2,5}$ Hence, we suppose that the pathogenesis of this "lung-heart" or "lung-vessel" disease may be indirectly associated with hypoxia-induced damage to the system which further needs investigation. The strengths of the present study are to find out a significant positive association between obstructive lung function tests and the cf-PWV which is a measure of arterial stiffness. Also, diastolic blood pressure and PP were found to be associated with severity of obstruction. Other factors like BMI, age were not significantly associated with the lung function impairment. The limitations of the present study are lack of data regarding hormonal status in the postmenopausal women, oxygen levels in the peripheral blood, and the estimation of biomarkers. These tests could not be performed in these women as they are out of scope of the study objectives.

\section{Conflict of Interest}

None.

\section{Acknowledgments}

We are extremely thankful to the WINCARS association for selecting our project under the Prajwalika Scholarship (PSS) program. We would like to thank the Faculty Department of Physiology for providing their expertise in conducting this study. We want to thank the Dean, Prof. Srinivas M. 
of our institute for giving continuous encouragement and support to actively get involved in the research. We extend our sincere thanks to the participants in the study.

\section{References}

1 Johnston AK, Mannino DM, Hagan GW, Davis KJ, Kiri VA. Relationship between lung function impairment and incidence or recurrence of cardiovascular events in a middle-aged cohort. Thorax 2008;63(7):599-605

2 Duprez DA, Hearst MO, Lutsey PL, et al. Associations among lung function, arterial elasticity, and circulating endothelial and inflammation markers: the multiethnic study of atherosclerosis. Hypertension 2013;61(2):542-548

3 Jankowich MD, Taveira T, Wu W-C. Decreased lung function is associated with increased arterial stiffness as measured by peripheral pulse pressure: data from NHANES III. Am J Hypertens 2010;23(6):614-619

4 Pan J, Xu L, Lam TH, et al. Relationship between pulmonary function and peripheral vascular function in older Chinese: Guangzhou biobank cohort study-CVD. BMC Pulm Med 2018;18(1):74

5 Okamoto M, Shipley MJ, Wilkinson IB, et al. Does poorer pulmonary function accelerate arterial stiffening?: a cohort study with repeated measurements of carotid-femoral pulse wave velocity. Hypertension 2019;74(4):929-935

6 Birhan MM, Abebe Y. Pulmonary function tests in hypertensive patients attending Zewditu Memorial Hospital, Addis Ababa, Ethiopia. Int J Hypertens 2018; ( 14):1:7

7 Swati S, Shaikh M, Gupta Y, Nahar P, Zingade U, Kowale A. Pulmonary function tests in hypertension. Int J Hypertens 2014;5(7):1-7
8 Silvestre OM, Nadruz W Jr, Querejeta Roca G, et al. declining lung function and cardiovascular risk: the ARIC study. J Am Coll Cardiol 2018;72(10):1109-1122

9 Wang B, Zhou Y, Xiao L, et al. Association of lung function with cardiovascular risk: a cohort study. Respir Res 2018;19(1):214

10 Li L, Hu B, Gong S, Yu Y, Dai H, Yan J. Pulmonary function and arterial stiffness in chronic heart failure. BioMed Res Int 2016;2016:5478394

11 Schnabel E, Nowak D, Brasche S, Wichmann HE, Heinrich J. Association between lung function, hypertension and blood pressure medication. Respir Med 2011;105(5):727-733

12 Amaral AFS, Patel J, Gnatiuc L, Jones M, Burney PGJ. Association of pulse wave velocity with total lung capacity: a crosssectional analysis of the BOLD London study. RespirMed (Baltimore) 2015;109:1569-1575

13 Medarov BI, Pavlov VA, Rossoff L. Dirunal variations in human pulmonary function. Int J Clin Exp Med 2008;1:267-273

14 Aggarwal AN, Agarwal R, Dhooria S, et al. Joint Indian Chest Society-National College of Chest Physicians (India) guidelines for spirometry. Lung India 2019;36(suppl) :S1-S35

15 Swanney MP, Ruppel G, Enright PL, et al. Using the lower limit of normal for the FEV1/FVC ratio reduces the misclassification of airway obstruction. Thorax 2008;63(12):1046-1051

16 Salpeter SR, Ormiston TM, Salpeter EE. Cardiovascular effects of $\beta$-agonists in patients with asthma and COPD: a metaanalysis. Chest 2004;125:2309-2321

17 Ohta K, Fukuchi Y, Grouse L, et al. A prospective clinical study of theophylline safety in 3810 elderly with asthma or COPD. Respir Med 2004;98(10):1016-1024

18 Xie A, Skatrud JB, Puleo DS, Morgan BJ. Exposure to hypoxia produces long-lasting sympathetic activation in humans. J Appl Physiol (1985) 2001;91(4):1555-1562 